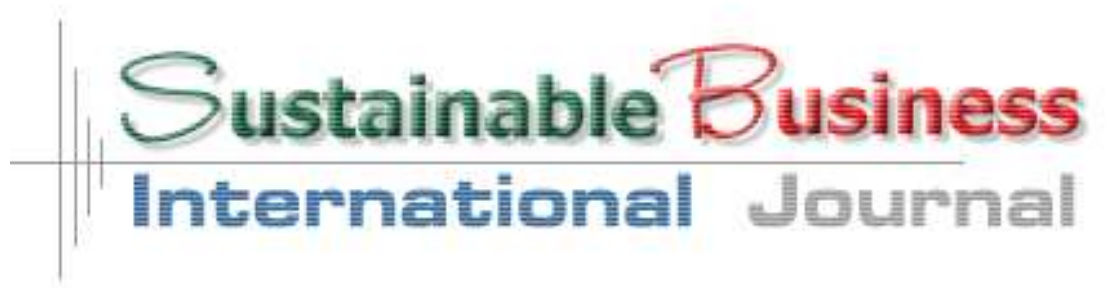

MAIO DE 2012- ISSN 1807-5908

\title{
ANÁLISE DA VIABILIDADE DE PRODUÇÃO DE BIODIESEL DE ÓLEO RESIDUAL DE FRITURA NA MARINHA
}

\author{
Aurelio Lamare Soares Murta, DSc - UFF ${ }^{1}$ \\ Marcos Aurelio Vasconcelos de Freitas, DSc - UFRJ ${ }^{2}$
}

\section{Resumo}

Este trabalho tem por objetivo analisar a possibilidade de produção de biodiesel para uso em veículos de frota cativa em unidades militares da Marinha, a partir do óleo residual de fritura utilizado nas cozinhas das unidades militares. Para tanto, foi realizado um levantamento acerca da disponibilidade de óleo nas principais unidades militares da Região Metropolitana do Rio de Janeiro e modelada uma rede de coleta deste material para encaminhamento a um centro de armazenagem e produção do biocombustível definido pelo próprio estudo. Para tanto foram levados em consideração aspectos de localização geográfica, bem como a malha viária disponível. Foram realizados, também, cálculos de custos de produção do biodiesel e dos insumos industrializados necessários ao processo. Ao final, foi possível calcular o preço final por litro (preço unitário) de biodiesel produzido e a economia resultante deste processo, bem como as possibilidades do uso deste biocombustível numa frota cativa experimental de veículos militares.

Palavras-chave: Logística; Sustentabilidade.

\footnotetext{
1 Possui graduação em Engenharia Civil pela Fundação Percival Farquhar - Univale (1999), Mestrado em Engenharia de Transportes pelo Instituto Militar de Engenharia - IME (2003) e Doutorado em Engenharia de Transportes pela Universidade Federal do Rio de Janeiro - PET/COPPE/UFRJ (2008). Atualmente é professor Adjunto do curso de Graduação em Administração da Universidade Federal Fluminense - UFF, do Programa de Pós Graduação em Administração da UFF (Mestrado), do MBA em Logística Empresarial e Gestão da cadeia de Suprimentos da UFF e Coordenador do Curso de Gestão Pública da UFF/UNIFA.

${ }^{2}$ Possui graduação em Geografia pela Universidade do Estado do Rio de Janeiro (1983), mestrado em Engenharia Nuclear e Planejamento Energético pela Universidade Federal do Rio de Janeiro (1988) e doutorado em Economie de l'Environnement - Ecole des Hautes Etudes en Sciences Sociales (1994). Atualmente é professor e Coordenador do Programa de Planejamento Energético da COPPE/UFRJ (desde 10/2011) e Coordenador Executivo do Instituto Virtual de Mudanças Globais (IVIG/COPPE/UFRJ) (desde 05/2005). Membro do IPCC - Grupo III - desde 2008, em Energias Renováveis. Tem experiência na área de planejamento energético e ambiental, com ênfase em Interdisciplinar de Energia, atuando principalmente nos seguintes temas: energia; regulação e gestão da água; licenciamento e gestão ambiental; mudanças climáticas; biomassa; desenvolvimento sustentavel e Amazônia. Foi Superintendente da Agência Nacional de Energia Elétrica (ANEEL), Diretor da Agência Nacional de Águas (ANA), Secretario Executivo do Centro Nacional de Referência em Biomassa e Adviser da Comissão de Hidrologia da Organização Mundial de Meteorologia (OMM).
} 


\begin{abstract}
This study aims to examine the possibility of producing biodiesel for use in fleet vehicles captive in military units of the Navy, from the residual oil used for frying in the kitchens of military units. For this, we conducted a survey on the availability of oil in the major military units in the metropolitan region of Rio de Janeiro and modeled a network of collecting this material for referral to a storage center and biofuel production set by the study itself. For both aspects were taken into account geographic location and the road network available. Were performed also calculations of the production costs of biodiesel and industrial inputs needed for the procedure. In the end, it was possible to calculate the final price per liter (unit price) of biodiesel and economy resulting from this process and the possibilities of using this biofuel in a captive fleet of military vehicles.
\end{abstract}

Key-words: Logistic; Sustainability.

\title{
1. INTRODUÇÃO
}

O Brasil apresenta um elevado potencial para produzir biocombustível, dentre eles o biodiesel, um combustível alternativo ao óleo diesel mineral, resultado do processo de transesterificação de óleos e gorduras, tendo sua origem a partir de óleos vegetais brutos, a exemplo da mamona, amendoim, soja e diversas outras culturas regionais possíveis de serem produzidas no território nacional, ou de óleo de fritura usado como será também, objeto deste estudo. Trata-se de um combustível utilizável em unidades descentralizadas de geração de energia elétrica, em equipamentos de produção, equipamentos agrícolas, máquinas para construção civil e em veículos usados para transporte de cargas e de passageiros.

Verifica-se que estes últimos respondem por cerca de $82 \%$ do consumo de óleo diesel, principal derivado de petróleo importado pelo país. Deste percentual, cerca de 97\% se destina exclusivamente ao modo rodoviário de cargas e passageiros (MME, 2009), que é o principal sistema da matriz de transportes brasileira, correspondendo a aproximadamente $61 \%$ de toda a carga transportada no país (ANTT, 2009).

A experiência internacional (Europa, Estados Unidos e Ásia) indica que esta alternativa pode levar a uma redução de emissões de gases de efeito estufa (GEE) e poluição atmosférica relacionadas à produção e uso de óleo diesel mineral. Ressalta-se que atualmente a Alemanha mantém uma frota de veículos a biodiesel, sendo 5\% de óleos reciclados. Já na França, todo o diesel combustível é misturado ao biodiesel na distribuidora ou refinaria em até 5\% (B5), recebendo o nome de diester. Exemplo semelhante ao da França ocorre no Brasil em termos de gasolina/álcool, onde toda gasolina comercializada possui em sua composição, cerca de $20 \%$ de álcool anidro, segundo Resolução $\mathrm{n}^{\circ}$. 35 do Ministério da Agricultura, Pecuária e Abastecimento. Além disto, grandes centros urbanos (como Paris) já estão testando a mistura de $10 \%$ (B10), já no Brasil, atualmente este percentual é de 5\% (B5).

Como objetivo principal este estudo busca demonstrar a viabilidade técnica e econômica, em caráter preliminar, da modelagem de uma rede de coleta de óleos residuais de fritura nas 


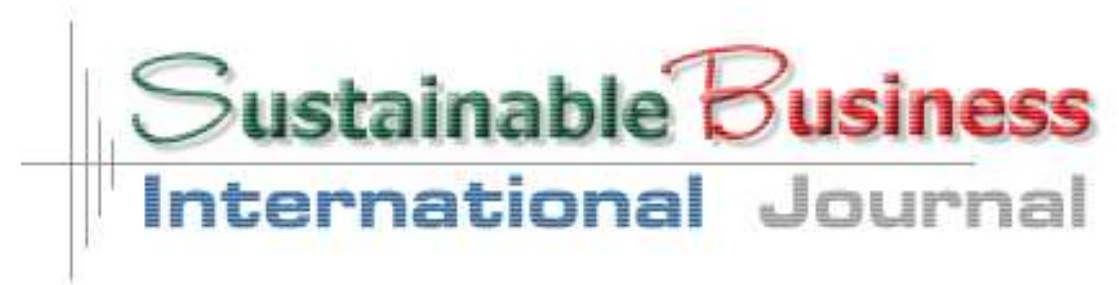

MAIO DE 2012- ISSN 1807-5908

cozinhas das Unidades Militares da Marinha, situadas na Região Metropolitana do Rio de Janeiro e, a utilização deste insumo para a produção e uso do biodiesel numa frota cativa experimental desta instituição. Como objetivos secundários serão quantificados e avaliados os custos logísticos e de produção inerentes a esta atividade, bem como a estimativa de custos unitários do biocombustível produzido.

\section{A LOGÍSTICA REVERSA E O MEIO AMBIENTE}

Atualmente as grandes cidades enfrentam dificuldades de destinação adequada dos seus resíduos sólidos e líquidos gerados pela população. Este fato pode ser observado pela inexistência de uma rede de coleta seletiva eficiente que separe os produtos coletados e que agregue valor a alguns destes produtos.

Como exemplo na cidade de Niterói com quase 480 mil habitantes, densamente povoada, onde são recolhidos diariamente cerca de 800 toneladas de resíduos, dos quais apenas 3\% a 4\% são reciclados (CLIN, 2009). Sabe-se que grande parte destes resíduos gerados, tanto nas residências como no comércio e instituições, é constituída por óleos comestíveis de fritura e que os mesmos são descartados inadequadamente, na maioria das vezes, em pias de cozinha ou misturado ao lixo.

Após este descarte o óleo segue para as estações de tratamento de esgoto, onde uma quantidade enorme de produtos químicos e filtragem física é demandada para a purificação desta água. Estima-se que o tratamento de esgoto torna-se cerca de $45 \%$ mais oneroso pela presença de óleos comestíveis nas águas servidas. Quando não há uma estação de tratamento de esgoto, este óleo vai direto para os cursos d’água ou baías, poluindo grandes porções de água (um litro de óleo polui cerca de um milhão de litros d’água). Isso acontece porque apesar de o óleo vegetal se dispersar em uma camada muito fina sobre a água, é suficiente para prejudicar a transferência de oxigênio na interface ar/água. Caso este óleo venha a cair na terra, como no caso dos lixões, poderá haver uma infiltração deste material no solo ocasionado a poluição de reservas subterrâneas de água (Ribeiro e Murta, 2007).

Acredita-se, preliminarmente, que grande parte do óleo utilizado pela Marinha na preparação de suas refeições está sendo descartado de forma inadequada ou não sendo aproveitado, com o potencial que poderia ser extraído deste material, caso o destino fosse devidamente planejado.

Verifica-se, portanto, que a maior parte do óleo não está concentrada em pontos únicos de coleta, mas sim dispersos em vários locais e em quantidades reduzidas, o que dificulta ou inviabiliza, financeiramente, a coleta por parte destas pequenas empresas já existentes. Entretanto, um cenário diferente pode ser observado na Marinha, onde os volumes estão concentrados nas unidades militares, o que facilita a coleta e posterior aproveitamento.

Deste modo, torna-se evidente a necessidade de se estudar a viabilidade econômica e logística de uma rede para a coleta deste material observando-se as restrições físicas, financeiras e geográficas. Esta rede deverá ser modelada seguindo-se os aspectos restritivos citados e sempre 
subsidiada por aspectos técnico-científicos constantes em bibliografia atualizada, que verse sobre o tema e experiências de aplicação da logística reversa em outros produtos.

A seguir na figura 01, está demonstrada a cadeia de retorno a ser estudada e que servirá como base para o estudo de modelagem da logística reversa do óleo residual de fritura. Esta cadeia de retorno, atualmente, representa o caminho da maior parte dos produtos que necessitam ser reincorporados nas atividades produtivas após serem descartados.

Assim, com a coleta e destino do óleo, grande parte da poluição e desperdício causado por este material deixará de existir, ou será minorada, contribuindo-se para um ambiente mais limpo e sustentável, ao mesmo tempo em que um material que antes era descartado estará novamente sendo inserido na cadeia produtiva.

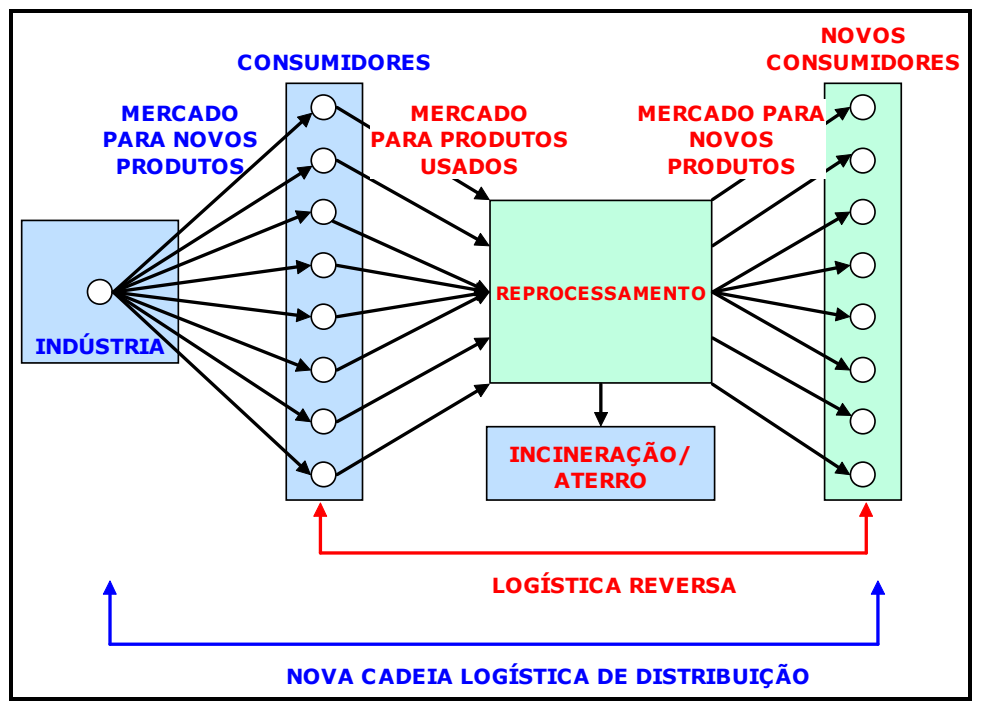

Figura 01: Canal de Distribuição e Retorno a ser Usado como Modelo

Fonte: Montenegro, 2003

No contexto da logística reversa, cabe ressaltar a crescente importância que a legislação ambiental acerca do assunto está assumindo no cenário da reciclagem e reaproveitamento de materiais descartados, apesar de diversas vezes observar-se dificuldade da aplicação prática desta legislação.

Deste modo, este estudo pretende demonstrar a possibilidade de se realizar a coleta do óleo de fritura e produção de biodiesel, caso sejam conhecidos e estabelecidos os parâmetros técnicos e as condições de contorno para a realização desta atividade.

\section{CONSIDERAÇÕES SOBRE A PRODUÇÃO DE BIODIESEL A PARTIR DE ÓLEO DE FRITURA}

A produção de biodiesel de óleo de fritura é possível graças ao processo físico-químico da transesterificação por rota metílica e catálise básica. Apesar de existirem outros, este processo 


\section{Sustainable Business

tem se mostrado mais eficiente quanto ao rendimento final, tempo de produção e melhor aproveitamento dos insumos (ou taxa de conversão de matéria-prima em produto acabado).

Para que este processo seja realizado, necessita-se de uma usina de transesterificação de óleos vegetais em ésteres metílicos com uma configuração semelhante à apresentada na figura 02 a seguir:

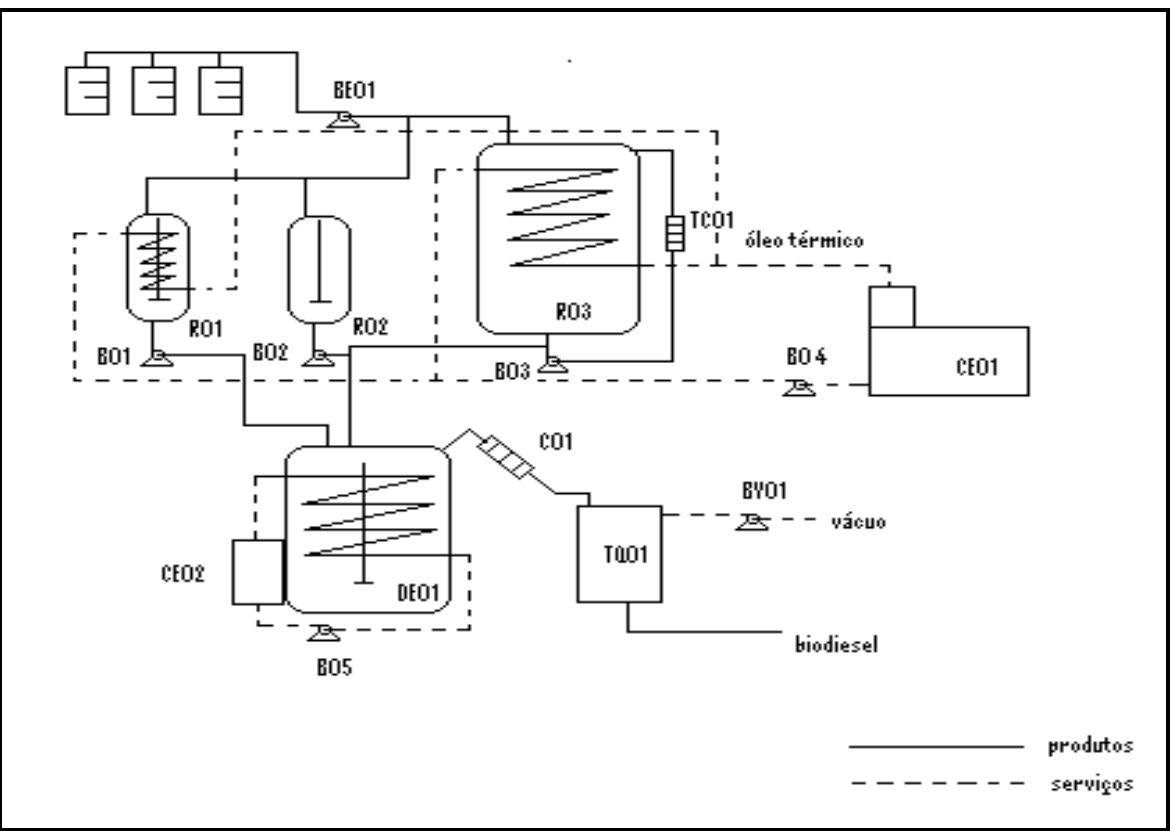

Figura 02: Diagrama da Unidade Piloto de Produção de Biodiesel da COPPE/UFRJ

Fonte: Murta et. al., 2006

A usina mostrada na figura está instalada na COPPE/UFRJ e produz biodiesel por batelada a partir de óleos vegetais virgens e usados em frituras. A seguir estão descritos todos os componentes demonstrados no fluxograma e suas respectivas funções:

BE01 - Bomba de engrenagem. Usada para transferência de matéria-prima para os reatores.

R01 - Reator fechado com sistema de aquecimento e agitação. Usado para transesterificação.

B01 - Bomba centrífuga. Usada para transferência de éster produzido no reator R01 ou R03.

R02 - Reator fechado com sistema de agitação. Usado para obtenção do alcoóxido (intermediário da reação do biodiesel) e para transesterificação.

B02 - Bomba centrífuga. Usada para transferência do alcoóxido ou éster produzido no reator R02.

R03 - Reator fechado com sistema de aquecimento e agitação. Usado para transesterificação e esterificação.

B03 - Bomba centrífuga. Usada para alimentação do trocador de calor (TC01) e retorno ao reator R03 para efeito de agitação.

TC01 - Trocador de Calor. Usado para resfriamento da massa reacional quando necessário. 


\section{Sustainable Business

CE01 - Caldeira elétrica. Usada para aquecimento de óleo térmico que fornece calor aos reatores R01 e R03.

B04 - Bomba centrífuga. Usada para circulação de óleo térmico para aquecimento dos reatores R01 e R03.

DE01 - Destilador. Usado para tratamento e purificação de biodiesel, através de destilação do biodiesel, recuperação de álcool e evaporação de água.

B05 - Bomba centrífuga. Usada para circular óleo térmico nas serpentinas internas do destilador DE01.

CE02 - Caldeira elétrica. Usada para aquecimento de óleo térmico que fornece calor ao destilador DE01.

C01 - Condensador. Usado para condensação dos destilados.

TQ01 - Tanque pulmão fechado. Usado para recolher o biodiesel destilado.

BV01 - Bomba de vácuo. Usada para gerar vácuo durante o processo de destilação.

Como insumos serão utilizados os seguintes produtos para a reação de transesterificação:

- Óleo de fritura usado;

- Álcool metílico $(\mathrm{MeOH})$;

- Hidróxido de potássio $(\mathrm{KOH})$.

O processo de produção do biodiesel realizado na unidade piloto de produção descrita acima está dividido nas seguintes etapas:

\section{Estequiometria da Reação:}

O óleo de fritura é levado a ensaio para verificar sua acidez, umidade e presença de sólidos. Depois de analisados estes quesitos será realizado o cálculo estequiométrico que determinará as proporções do óleo e dos reagentes químicos.

\section{Carregamento:}

A carga será adicionada no Reator R02 na seguinte ordem:

$1^{\circ}$ - álcool metílico.

$2^{\circ}$ - hidróxido de potássio.

Agitação durante 10 minutos para total dissolução do $\mathrm{KOH}$ no $\mathrm{MeOH}$ e formação do intermediário ativo (metóxido).

$3^{0}$ - Sobre o metóxido, adiciona-se o óleo de fritura.

\section{$>$ Transesterificação:}

Após o carregamento total dos insumos (conforme descrito no item 2), a reação se processa por cerca de 60 minutos com agitação, à temperatura e pressão ambientes.

\section{Recuperação do Álcool:}

Após a reação, a mistura será transferida para o destilador DE01 onde álcool não reagido (excesso), será recuperado por destilação a vácuo. 
Separação Éster/Glicerol:

Após a recuperação do álcool, separa-se por decantação o glicerol para ser armazenado em tanque apropriado.

\section{Tratamento do éster:}

$\mathrm{O}$ éster obtido necessita ser tratado por lavagem com água à temperatura ambiente. Geralmente se utilizam 03 (três) lavagens, sendo a $1^{\circ}$ sem agitação. Após a lavagem, retira-se a água decantada e aquece-se o éster a $120^{\circ} \mathrm{C}$ para retirada total da água.

Após ser produzido, o biodiesel deverá ser armazenado em tanque apropriado e amostras deverão ser colhidas e enviadas a um laboratório de análises químicas para especificação ou posteriores correções. Isto garantirá a qualidade e segurança do combustível produzido de modo que o mesmo possa ser utilizado em veículos a diesel.

\section{METODOLOGIA PARA A MONTAGEM DA REDE LOGÍSTICA}

\subsection{Cadeia de Produção, Distribuição e Uso de Biodiesel de Óleo de Fritura}

Conforme comentado, a cadeia de produção e distribuição do biodiesel no Brasil torna-se bastante complexa à medida que os pontos de coleta vão se multiplicando, e conseqüentemente a freqüência e quantidade coletada vão sendo reduzidas. Isto acaba fazendo com que os custos logísticos fiquem maiores devido à operação ser mais onerosa e a infra-estrutura despendida tornar-se mais robusta.

Entretanto, no caso do aproveitamento dos óleos de fritura na Marinha, os custos deverão se colocar em patamar bem abaixo do que foi visto anteriormente. Este fato se deve pela não necessidade de compra do óleo de fritura usado (já se encontra disponível nas unidades militares), pela concentração das quantidades de óleo em determinados pontos, pela similaridade nas freqüências de coleta e pela possibilidade de aproveitamento da infra-estrutura logística já existente na instituição para deslocamentos diversos.

Deste modo, a rede de coleta e produção de biodiesel na Marinha deverá ser configurada da seguinte forma, conforme figura 03 a seguir:

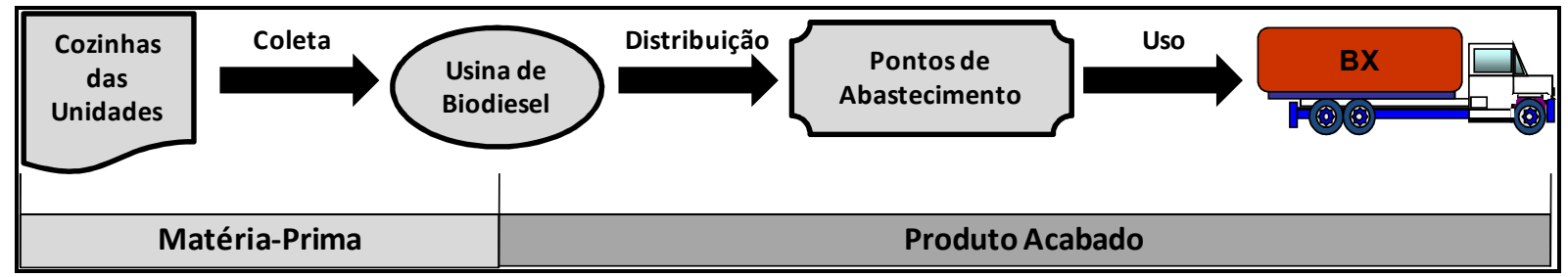

Figura 03: Cadeia a ser utilizada no estudo

Fonte: Elaboração própria, 2009. 


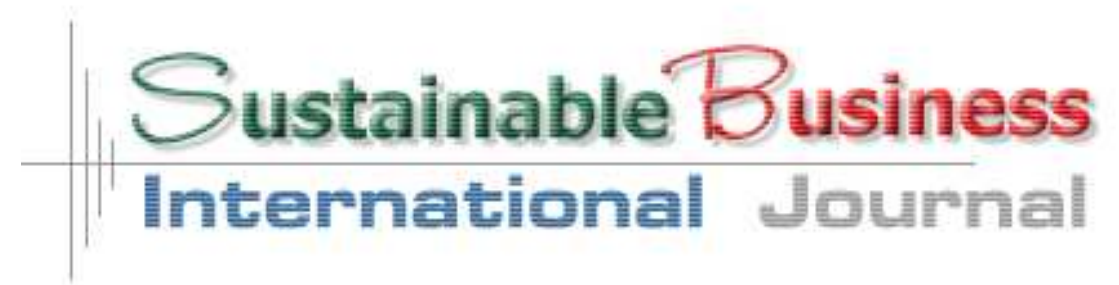

MAIO DE 2012- ISSN 1807-5908

Apesar de o funcionamento ter sido bastante simplificado, algumas etapas necessitam de procedimentos operacionais e técnicos específicos de modo a garantir a qualidade e continuidade de todo o processo, conforme será descrito a seguir.

\subsection{Coleta do Óleo Residual}

Esta etapa inicial requer desenvolvimento de uma rede logística reversa capaz de assegurar o suprimento contínuo de óleo para posteriormente ser encaminhado à unidade produtora de biodiesel. Imagina-se que ações voltadas à conscientização por parte dos profissionais envolvidos no preparo dos alimentos nas cozinhas seriam de suma importância. Isto se faz necessário para que sejam estabelecidos padrões de utilização deste produto, separação de resíduos sólidos, bem como a correta armazenagem do mesmo até a coleta.

Em longo prazo poderia se implantar a coleta o óleo utilizado nas residências das vilas militares através da coleta seletiva, já conhecida pela população, porém pouco incentivada, onde um recipiente apropriado seria designado a receber o óleo utilizado na fritura dos alimentos, que seria posteriormente coletado.

Nesta etapa, a qualidade do óleo coletado está diretamente ligada à qualidade do combustível e à taxa de conversão do óleo em biodiesel, ou seja, quanto maior o número de reutilizações do óleo, menor será o rendimento do mesmo em biodiesel. Assim, se faz importante a correta utilização do óleo a ser usado em fritura, evitando seu uso em demasia, o que além de acarretar problemas à saúde, diminui a qualidade do mesmo, como matéria-prima para produção de biodiesel. Como exemplo, pode se observar que em grandes cozinhas industriais a presença constante de um nutricionista profissional garante esta correta utilização do óleo, o que conseqüentemente assegura a qualidade do insumo.

\subsection{Produção de Biodiesel}

Nesta fase se dá efetivamente a produção industrial do éster que será posteriormente enquadrado nas normas da Agência Nacional do Petróleo (ANP), para que somente depois possa ser utilizado na frota de teste. Requer-se nesta fase, um desenvolvimento tecnológico capaz de propiciar melhor qualidade na produção, inclusive levando-se em consideração as diferenças na qualidade das fontes de óleos usados para fritura disponíveis nas unidades militares. Também será necessária, a implantação da usina de produção de biodiesel que deverá estar localizada preferencialmente em uma das unidades militares que possua um posto de abastecimento de combustíveis, o que permitirá a realização mistura diesel/biodiesel, proporcionando economia de transporte do produto acabado e segurança na operação.

Com relação à qualidade do produto acabado, a ANP possui normas para a produção de biodiesel em escala comercial e experimental que visam garantir a confiabilidade de que o produto fabricado atende especificações mínimas necessárias ao correto funcionamento dos motores a diesel. Assim, amostras do biodiesel produzido deverão passar por análises químicas para enquadramento nestas especificações da ANP conforme sua utilização. 


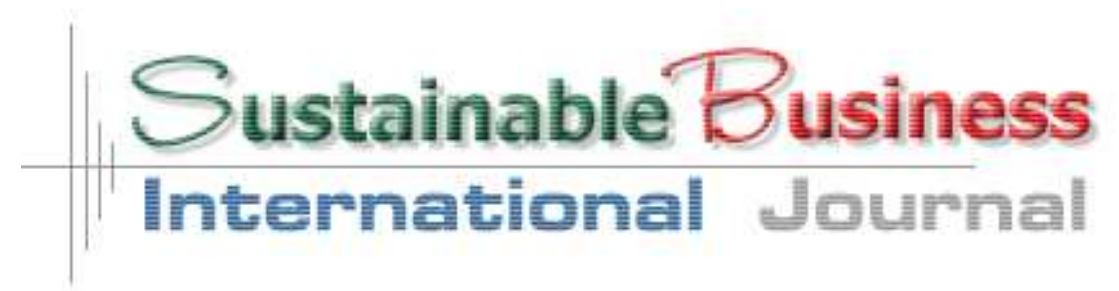

MAIO DE 2012- ISSN 1807-5908

\subsection{Pontos de Abastecimento}

Nestes pontos será realizada a mistura entre o óleo diesel de origem mineral e o biodiesel já enquadrado nas especificações da Agência Nacional do Petróleo (ANP). Estes pontos tornam-se importantes, uma vez que a precisão no percentual de mistura será totalmente controlada nesta etapa da cadeia.

No caso da distribuição de biodiesel para estes locais, uma infra-estrutura para esta finalidade deverá ser criada, entretanto será inserida na infra-estrutura já existente para os demais combustíveis aproveitando-a. Tal estrutura deverá constar de tanques com dispositivos de abastecimento onde será possível a realização da mistura no percentual pré-definido.

Adicionalmente, sabe se que a intenção do governo é a de fornecer o biodiesel já adicionado ao diesel. Atualmente este percentual é de $5 \%$ de biodiesel misturado a $95 \%$ de óleo diesel comum (ANP, 2009). Deste modo, verifica-se que esta iniciativa de "autoprodução" poderá antecipar as perspectivas do Governo em aumentar os percentuais de biodiesel na mistura e contribuir para o desenvolvimento científico e tecnológico da produção e uso do biodiesel em motores, pelo fato de fornecer informações e conhecimento acerca do assunto.

\subsection{Uso nos Veículos da Frota}

Nesta etapa a mistura Diesel/Biodiesel deverá ser recebida em condições apropriadas para uso, inclusive com certificação, para que seja utilizado pelos veículos da frota. É importante ressaltar que em alguns países, além do biodiesel já misturado na distribuidora/refinaria, os postos de combustíveis ainda permitem a compra de biodiesel puro (100\% biodiesel), facultando assim ao consumidor efetuar no tanque do veículo a mistura na proporção que lhe for conveniente, como acontece no Brasil com os veículos bicombustíveis (gasolina/álcool). Entretanto, a atual intenção deste estudo é utilizar o produto já misturado nas quantidades experimentais permitidas pela ANP.

Salienta-se que os veículos que utilizarão a mistura deverão ser monitorados e checados periodicamente a fim de se identificarem possíveis alterações no funcionamento, desgaste prematuro de componentes e demais anomalias identificáveis. Isto se faz necessário para que a garantia de correto funcionamento, bem como a segurança dos veículos e seus ocupantes seja sempre preservada.

\section{MODELAGEM DA REDE DE PRODUÇÃO E USO DO BIODIESEL}

A seguir será descrito o modelo a ser implementado segundo os dados e informações coletadas junto às unidades militares utilizadas no estudo. Salienta-se que algumas informações foram estimadas durante os cálculos, com as devidas justificativas. Este fato se deveu em função da dificuldade de obtenção de informações mais precisas e em tempo hábil para a realização deste trabalho. 


\section{Sustainable Business International Joumnal}

\subsection{Localização das Unidades Militares}

Optou-se, durante a escolha das unidades militares que seriam as grandes geradoras de óleo residual de fritura, em considerar aquelas de maior contingente de servidores. Deste modo, estimou-se a quantidade provável de óleo para estas unidades que possuem cozinhas.

Salienta-se que foi realizado um exercício de localização de unidades militares (UM) coincidente com a localização de unidades reais existentes na Marinha, cujos nomes oficiais não foram descritos neste trabalho por questões de sigilo de informações de Órgão de Defesa. O exercício de localização tornou-se necessário de modo a permitir que o método de cálculo, bem como os valores a serem trabalhados, fossem estimados com o máximo de fidelidade. A seguir, na figura 04, podem ser observadas as localizações das unidades militares estipuladas para o estudo e suas distâncias rodoviárias reais.

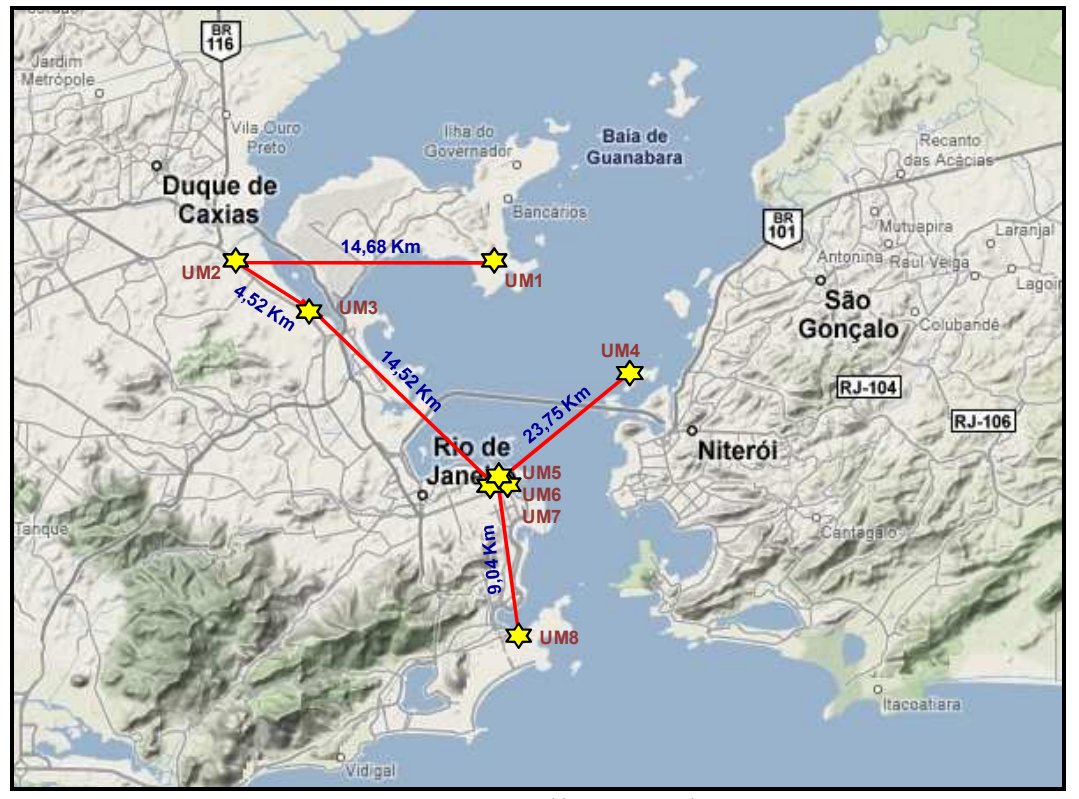

Figura 04: Localização das UM

Fonte: Marinha do Brasil (2009), Google Maps (2009) e Elaboração própria (2009).

\subsection{Cálculo da Quantidade de Óleo Disponível}

Segundo dados do IBGE (2005) a razão de aquisição de óleo comestível virgem pela população brasileira é de 6,3 litros/ano/habitante.

Deste modo, a partir do número de refeições diárias servidas por cada UM foi possível se estimar a quantidade de óleo residual mensal gerado nas unidades consideradas. Foram consideradas perdas de $30 \%$ do óleo utilizado devido ao processo de evaporação, desperdícios e absorção pelos alimentos usados na fritura (Ribeiro e Murta, 2007).

Na tabela 01 pode se observar a quantidade de óleo residual de fritura estimado para o estudo: 


\section{Sustainable Business International Joumal}

MAIO DE 2012- ISSN 1807-5908

Tabela 01: Quantidade de Óleo Estimada por UM

\begin{tabular}{cccc}
\hline Unidades Militares & Refeições Diárias & $\begin{array}{c}\text { Volumes Semanais sem } \\
\text { Perdas (I) }\end{array}$ & $\begin{array}{c}\text { Volumes Mensais com } \\
\text { Perdas (I) }\end{array}$ \\
\hline UM1 & 850 & 103 & 288 \\
UM2 & 1200 & 145 & 407 \\
UM3 & 1000 & 121 & 339 \\
UM4 & 1500 & 182 & 509 \\
UM5 & 750 & 91 & 254 \\
UM6 & 1000 & 121 & 339 \\
UM7 & 800 & 97 & 271 \\
UM8 & 600 & 73 & 204 \\
\hline
\end{tabular}

\subsection{Definição do Local de Armazenagem e Produção}

Com base na localização geográfica das unidades militares consideradas e suas quantidades mensais foi possível definir a melhor localização para a implantação do centro de armazenagem do material coletado e da usina de biodiesel a ser instalada. Ressalta-se que por questões de proximidade geográfica as unidades militares 5, 6 e 7 foram agrupadas em uma única.

Para tal utilizou-se o método de localização de instalação por momentos ou método dos momentos, que consiste na ponderação um determinado centro (UM) em relação aos demais centros existentes em uma determinada região geográfica (Ballou, 2003).

$$
\mathrm{MM}=\Sigma \mathrm{CT} \times \mathrm{V} \times \mathrm{D}
$$

Onde, MM: método dos momentos, CT: custo unitário de transportes, V: volume gerado e D: distância

Assim, segundo SIFRECA (2009), considerando-se um frete de R\$ $0,15 / \mathrm{m}^{3}$. Km para o transporte de óleos vegetais tem-se: $\mathrm{MM}_{\mathrm{UM} 1}=\mathrm{R} \$ 8,34 ; \mathrm{MM}_{\mathrm{UM} 2}=\mathrm{R} \$ 4,80 ; \mathrm{MM}_{\mathrm{UM} 3}=\mathrm{R} \$ 4,19$; $\mathrm{MM}_{\mathrm{UM} 4}=\mathrm{R} \$ 6,99 ; \mathrm{MM}_{\mathrm{UM} 5,6 \text { e } 7}=\mathrm{R} \$ 3,42$ e $\mathrm{MM}_{\mathrm{UM} 8}=\mathrm{R} \$ 5,51$.

Deste modo, com base apenas nos cálculos realizados pode-se constatar que o complexo formado pelas unidades militares 5, 6 e 7, que apresentou o menor momento de transporte, deverá ser escolhido para sediar o centro de armazenagem da coleta e da instalação da usina de biodiesel.

\subsection{Definição dos Parâmetros de Produção de Biodiesel}

Uma vez tomada a decisão acerca do local da fabricação do biodiesel, deverão ser realizados os cálculos econômicos da produção do biocombustível para uso na frota em teste.

Segundo dados de Murta (2008) para a fabricação de biodiesel de óleo de fritura são necessários como reagentes: $82,64 \%$ de óleo de fritura, $16,53 \%$ de metanol e $0,83 \%$ de catalisador (potassa cáustica). Após a reação de transesterificação os produtos resultantes são: $83,33 \%$ de ésteres metílicos, $10 \%$ de glicerol e $6,67 \%$ de metanol recuperado, que poderá ser reutilizado em bateladas posteriores. Ressalta-se que caso haja necessidade, poderá ser adicionado no produtos 
final $0,5 \%$ de aditivo antioxidante que variará em virtude do grau de acidez do óleo de fritura utilizado como insumo.

A seguir na tabela 02, pode-se observar os preços médios dos insumos praticados no mercado, ressaltando-se que foi atribuído um custo de $\mathrm{R} \$ 0,50$ por litro de óleo uma vez que o mesmo, atualmente, tem sido negociado pelas unidades militares na troca por produtos de limpeza. Deste modo, apesar do óleo já pertencer à instituição e não necessitar ser comprado, este valor atribuído cobrirá, proporcionalmente, as despesas com a aquisição dos produtos de limpeza pelo setor de compras.

Tabela 02: Preço Médio dos Insumos no Mercado

\begin{tabular}{|l|ll|}
\hline Insumo & \multicolumn{2}{|c|}{ Preço/litro } \\
\hline Óleo Fritura & $\mathrm{R} \$$ & 0,50 \\
\hline Metanol & $\mathrm{R} \$$ & 1,49 \\
\hline $\mathrm{KOH}$ & $\mathrm{R} \$$ & 1,62 \\
\hline Aditivos & $\mathrm{R} \$$ & 2,00 \\
\hline
\end{tabular}

Fonte: Prosint (2009) e Panamericana (2009).

Com a geração estimada de 2.612 litros de óleo de fritura torna-se possível a produção de cerca de 2.634 litros de biodiesel (Murta, 2008). Assim, será necessária uma quantidade de insumos para o processo de transesterificação, conforme mostrado na tabela 03 a seguir:

Tabela 03: Insumos Necessários à Produção

\begin{tabular}{|l|r|}
\hline \multicolumn{1}{|c|}{ Insumo } & \multicolumn{1}{c|}{ Quant. (litros) } \\
\hline Produção Mensal Biod. & $2.633,84$ \\
\hline Óleo de Fritura & $2.612,08$ \\
\hline Metanol & 259,76 \\
\hline $\mathrm{KOH}$ & 21,77 \\
\hline Aditivos & 13,17 \\
\hline
\end{tabular}

Em relação aos custos gerais do processo de coleta e produção do biodiesel de óleo de fritura nas unidades militares da marinha pode-se observar, na tabela 04 , que os insumos contribuem com a maior parte dos custos do processo, seguido da logística e impostos.

Tabela 04: Custos Operacionais

\begin{tabular}{|l|lr|}
\hline \multicolumn{1}{|c|}{ Atributo } & \multicolumn{2}{c|}{ Valor } \\
\hline Materia-Prima & $\mathrm{R} \$$ & $1.754,68$ \\
\hline Impostos & $\mathrm{R} \$$ & 251,98 \\
\hline Logística & $\mathrm{R} \$$ & 274,88 \\
\hline Transformação & $\mathrm{R} \$$ & 6,87 \\
\hline Salários & $\mathrm{R} \$$ & 2,29 \\
\hline Total & $\mathrm{R} \$$ & $2.290,70$ \\
\hline
\end{tabular}

Assim, o custo de final por litro de biodiesel produzido a partir do óleo de fritura coletado nas unidades militares utilizadas neste estudo foi de $\mathrm{R} \$ 0,87$. Este preço está bem abaixo do preço do diesel comercial que situa-se no patamar dos $\mathrm{R} \$ 2,00$. 


\section{Sustainable Business International Joumal}

Salienta-se que o método de cálculo dos custos é semelhante à produção comercial de biodiesel, o que adiciona valores de impostos e salários. Parte destes custos poderá ser suprimida caso as unidades militares produzam biodiesel apenas para uso interno e utilizando mão-de-obra já remunerada.

\section{ANÁLISE CONCLUSIVA}

Observa-se, pelo estudo, que é possível a produção de biodiesel para uso em frota cativa em unidades militares da Marinha de modo econômico. O volume produzido e os valores encontrados proporcionam uma economia de cerca de 57\% (R\$ 2.952,38) em detrimento à compra do óleo diesel comercial utilizado normalmente.

Este volume permite o uso mensal da mistura B10 (10\% de biodiesel em 90\% de diesel) em 24 caminhões ou B15 em 12 caminhões ou B20 em 8 caminhões ou ainda, B30 em 5 caminhões. Salienta-se que estes percentuais já consideram a venda comercial do diesel contendo $5 \%$ de biodiesel conforme instituído pelo Governo Federal a partir de janeiro de 2010.

Pode-se constatar também, pela figura 05, que a evolução do preço do biodiesel comercializado nos leilões promovidos pela ANP, para aquisição do produto, situa-se em média, num patamar quase 2 vezes superior ao preço do biodiesel proveniente da proposta de produção própria na Marinha.

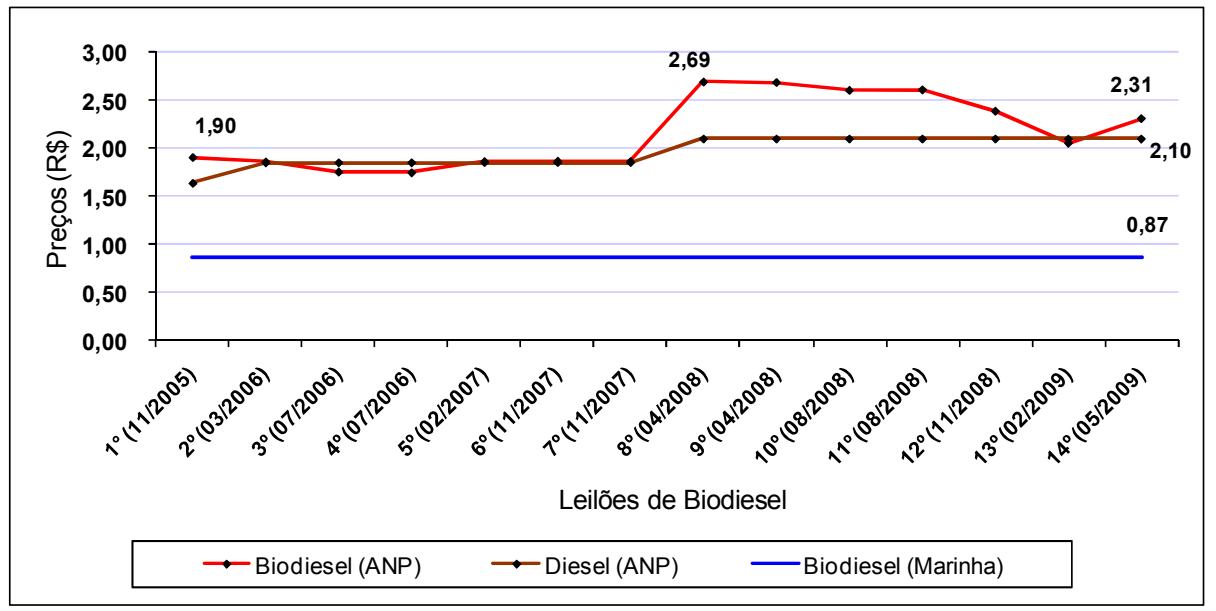

Figura 05: Evolução do Preço do Biodiesel nos Leilões da ANP Fonte: Elaboração Própria a partir de ANP (2009)

Por fim, dentre os percalços observados no decorrer do estudo, salienta-se a dificuldade de coletar dados mais precisos acerca da geração de óleo em todas as unidades militares, o que forçou a obtenção de alguns dados por estimativas numéricas e estatísticas. Esta dificuldade também fez com que outras unidades militares fossem descartadas do estudo devido à não existência mínima dos dados confiáveis necessários às estimativas. 


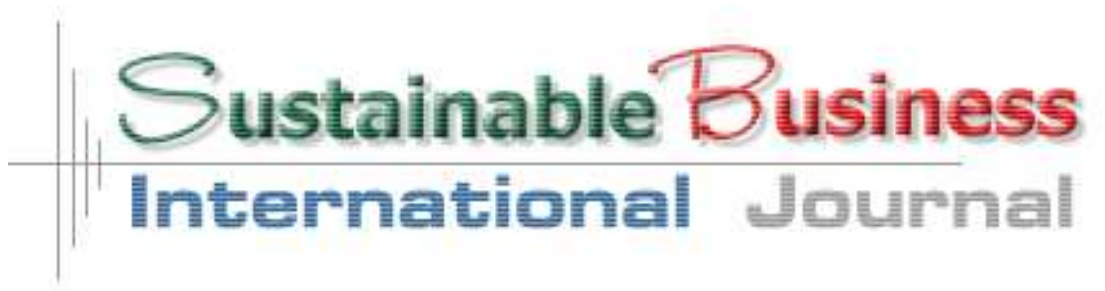

MAIO DE 2012- ISSN 1807-5908

\section{REFERÊNCIAS BIBLIOGRÁFICAS}

ANP (2008) - Estatística sobre o consumo de óleo diesel no Brasil e as importações. Agência Nacional do Petróleo, Rio de Janeiro.

ANTT (2009) - Transporte de Cargas/Transporte Rodoviário. Agência Nacional de Transportes Terrestres. Disponível em: http://www.antt.gov.br/

BALLOU, R. H.; 2003, Gerenciamento da Cadeia de Suprimentos, $4^{\mathrm{a}}$ edição, Ed. Bookman, São Paulo, SP.

CLIN - COMPANHIA DE LIMPEZA DE NITERÓI, 2009, estatísticas de coleta urbana, disponível em: http://www.clin.rj.gov.br/nova/index.php?a=empresa.

MINISTERIO DAS MINAS E ENERGIA (2009) - BEN Balanço Energético Nacional. Disponível em: http://www.mme.gov.br/

MONTENEGRO, L. C. S.; Logística Reversa: Custos e Benefícios Associados; Dissertação de Mestrado, Instituto Militar de Engenharia - IME, Rio de Janeiro, RJ, 2003.

MURTA, A. L. S; RIBEIRO, S. K.; O USO DO BIODIESEL DE ÓLEO DE FRITURA NO BRASIL - Resultado de Testes de B5 em Frota Cativa de Caminhões, Artigo Científico Publicado do Congresso: Associação Nacional de Pesquisa e Ensino de Transportes - ANPET, 2006.

MURTA, A. L. S; ANÁLISE DA VIABILIDADE DE AUTOPRODUÇÃO DE BIODIESELPOR FROTISTAS: O CASO DA VALE; Capítulo 4; Tese de Doutorado defendida em 2008 pelo Programa de Engenharia de Transportes da COPPE/Universidade Federal do Rio de Janeiro - UFRJ; Rio de Janeiro, RJ.

PROSINT Química S.A., 2009, Metanol, disponível em: http://www.prosint.com.br/prosint.htm e Cotação de metanol encaminhada em 2009, Rio de Janeiro, RJ.

PANAMERICANA S.A Indústrias Químicas; disponível em: http://www.panamericana.com.br/panamericana/ e Cotação de hidróxido de potássio encaminhada em 2009, Rio de Janeiro, RJ.

RIBEIRO, S.K.; MURTA A.L.S. (2007) Programa de Reaproveitamento de Óleos Vegetais do Estado do Rio de Janeiro - PROVE, Secretaria de Estado do Ambiente - SEA, Governo do Estado do Rio de Janeiro, Rio de Janeiro-RJ.

SIFRECA (2009) - Sistema de Informações de fretes, consultado em 2009 e disponível em : http://sifreca.esalq.usp.br/sifreca/pt/index.php 